\title{
THE PROBLEM OF VENEREAL DISEASE IN THE MERCANTILE MARINE*
}

By H. M. HANSCHELL, D.S.C., M.R.C.S., D.T.M. \& H., Hon. Medical Superintendent, Seamen's Hospital, Royal. Albert Dock, London

Mr. President, Ladies and Gentlemen,

I propose to put before you, as briefly as I can, an opinion on the matter of venereal disease (V.D.) in the Mercantile Marine, founded on my own experience of these diseases in the seafarers of one part of the straggling port of London.

Practically in the centre of three great docks, the Royal Albert and Victoria and the King George V. Docks, lies the Seamen's Hospital, and ten years' charge of the V.D. department of this hospital, involving the medical care of nearly 7,000 seafarers of every nationality, creed and colour, with actual or suspected V.D., has given me two impressions, namely :-

First, and most important, the seafarer sailing in and out of these docks is most anxious to seek expert medical advice and treatment for V.D., and that without loss of time.

Second, V.D. itself in the seafarer differs in no clinical, microbial, pathological, serological or therapeutical character from V.D. in the landsman. Observation of many landsmen with V.D. attending my clinic has easily established that conclusion. Epidemiologically there is this difference, that chancroid is certainly more common in the seafarer than in the landsman.

I shall leave out of consideration all purely medical matters; though I recognise fully that they are at least one half, and perhaps the more important half, of the problem, insomuch that any improvement in treatment which would make the V.D. seafarer more quickly noninfectious to others at once simplifies and makes easier the prevention of V.D.

* Read before the Medical Society for the Study of Venereal Diseases, April 5th, 1929. 
V.D. in the seafarer is a reflection of V.D. in the landsman ; there has been the same steady decrease in primary and secondary syphilis, equally in both classes of patient.

More than half the V.D. cases in the White seafarers (and it is only from them that it has been possible by cross-examination to get any sort of reliable history) appear to have been infected in England-mostly London ; and the great majority of all cases wherever acquired were the result of paid-cash-for sexual transactions at home and abroad, and so presumably with professional prostitutes.

An increasing number of seafarers have sought examination for fear of having contracted V.D. ; thus, of the last consecutive 708 White seafarers attending my clinic, I24 were found not to be suffering from V.D.

The very great majority of all the seafarer cases have been aged from eighteen to twenty-seven years.

I have a considerable quantity of records showing the apparent countries of infection. But this is an index rather of the shipping trade with those countries to and from the Royal Victoria and Albert Docks and the King George V. Dock than of the extent of V.D. in those countries. For example, to give a few figures, of the last consecutive 700 White seafarers, ro were apparently infected in North America, 32 in Australasia, 52 in South America, 80 in India and the Far East.

Again, of the last 900 consecutive seafarers, 200 were Asiatics or negroes.

Of course, the traveller carries disease with him. Perhaps disease to-day is carried across the seas from country to country more by the passenger than by those who work the ship, for passengers have for many years largely outnumbered crews; and venereal disease is, if anything, more easily and carefully hidden in, and by, the passenger than in the seaman. Any doctor, for instance, who examines men, non-seafarers, returning from the East or from other tropical lands, knows how often these bring contagious V.D. home with them.

No medical inspection of passengers has yet been extended to critical clinical examination of the genitalia, nor are laboratory tests exacted for them ; while all crews of ships in the ports of Great Britain are medically examined before signing on a ship for a voyage. It thus happens, in fact, that the majority of seafarers in this 


\section{BRITISH JOURNAL OF VENEREAL DISEASES}

country are medically inspected twice a year at least, and very many thrice a year.

It is true that this medical examination of seafarers before they sign on as members of a crew cannot in reasonable practice be made so thorough as to detect every case of contagious or infectious V.D., but such as it is, it does detect the great majority of such cases. And, what is of great importance, it brings cases so detected promptly under treatment.

Medical Examination of Crews before Signing ON

Stewardesses are medically examined, but no genital or " pelvic" examination is carried out.

As to the men-those signing on in the Royal Albert and Victoria Docks and in the King George V. Dock of the Port of London are thoroughly examined, and in this examination attention is paid to V.D.

I am happy in that I have received during ten years much assistance in the working of the V.D. clinic at the Seamen's Hospital, Royal Albert Dock, from Dr. John Brown, whose duty it is to carry out these signing-on examinations. The resources of the clinic are always at his disposal. Any doubtful case picked out by him, or his Assistant Medical Officer, is directed to go for examination to the clinic, which is, in fact, near at hand (an ideal arrangement).

Though many of the cases so sent turn out not to be V.D., yet during ten years no one has complained, even though delay in making a diagnosis has often lost the man his chance of signing on that particular ship. If the case be found at the clinic to be not venereal disease, a report to that effect is given to the man and is later accepted by the examining doctor.

That there have been no complaints is a tribute to the examining doctor's professional tact, and no less to the seafarers' reasonable common sense and good nature. In fact, every case, so far, has been rather pleased to have had his condition investigated. If V.D., usually then a urethritis, treatment has been readily accepted.

I suggest that some such close working connection between the business of the medical examination of crews before signing on and a V.D. clinic is necessary. It should not be, it need not be, official or legally obliga- 
tory. The seafarer did not, to begin with, accept very readily this signing-on medical examination. It was not set up primarily in his interest, nor in that of the public health ; but by the shipowners primarily in their interest, to protect themselves from possible unwarranted claims by the men for compensation for injury or illness suffered while in the owners' ships. To-day, in so far as V.D. is concerned, it is an examination in the interest of seafarer and public health and shipowner.

It is, however, essential that the V.D. clinic be near to the place where the signing-on medical examination takes place, and be open every and all day.

The Seafarers' Unions in this country support, in general, efforts to weed out cases of V.D. from the crews, and the seafarers as individuals are in favour of this attempt. In fact, I have learnt from the seafarer with V.D. himself that he objects to it in others in the same ship as himself.

\section{INSTRUCTION}

Printed notices are posted in the docks, giving warning information about V.D. and the situation and sessions of the V.D. clinics, and notices to this effect are distributed to the ships for the information of the crews by the Port Sanitary Authority.

\section{At SEA}

It must sometimes happen that though no signs of V.D. were detectable at the signing-on medical examination, yet later, and now at sea, V.D. manifests itself.

If the ship carries a surgeon-and to-day most British crews are in ships that do-the patient may receive prompt treatment. I judge from my patients' own statements that treatment is given. The surgeon does treat the case to the extent of his equipment in knowledge, drugs and apparatus ; and, moreover, often advises the patient where to go for treatment on landing. But there has been plainly considerable variation in the surgeons' equipment. In the past many ships' surgeons have had no first-hand experience of the modern methods of diagnosis or treatment of V.D., and few ships to-day carry either irrigation apparatus or such drugs as salvarsan or bismuth. This, of course, exactly reflects the past neglect of V.D. in the medical schools. 
All this, however, seems to be changing, and for the better, even if but slowly.

During the last five years - and the time noted by me is again, I think, a reflection of the new attention given to V.D. in the medical schools-it has been evident that many ships' surgeons are in possession of (some shipprovided, some self-provided) irrigation apparatus and salvarsan and bismuth preparations, and know how to, and do, use them. There is a more careful differential diagnosis of chancres. Buboes are often sterilely aspirated, instead of made septically worse by incisions. Not a few patients come to the clinic with careful notes on their cases by the ship's surgeon, who himself may come to the clinic with his patients. Those that I have so met have confessed to a post-graduate attendance at a V.D. clinic before going to sea as ship's surgeon.

Now most steamship lines have a waiting list of applicants for the post of surgeon: and V.D. clinics are accessible enough.

I suggest as a needed reform that owners demand of applicants for the post of ship's surgeon proof of a postgraduate attendance at a V.D. clinic, and responsible testimony to the effect that the applicant is able to deal with V.D. cases in the light of modern knowledge of diagnosis and treatment.

There would be no expense for the owners, and practically none for the would-be ship's surgeon, who, as it is, must usually wait several weeks or months for a ship.

The V.D. clinics have had a beneficial educative effect even on the layman member of a ship's crew ; for even if the ship carry no surgeon, the steward who treats the V.D. cases obviously now often gives treatment along lines learnt at first hand in a V.D. clinic or from some one who has so learnt-that is to say, caustics and strong antiseptic lotions are no longer used ; instead, weak antiseptics and cleanliness are prescribed until the patient can reach a doctor.

Many seafarers now carry a portable urethral irrigation apparatus as part of their gear, and find a way to use it on board ship, and sometimes even instruct a shipmate in its use.

It does not appear to me impossible or even unreasonable that some such outfit should be an obligatory part of the ship's medical equipment. 
Modern voyages are short ones, and even on those of three and four months there are several ports of call, and at many of these ports there is being made slowly increasing provision for the treatment of V.D. in seafarers. Few may now, in fact, sea-voyage for a month before getting within reach of medical advice and treatment. Obviously, then, a higher level of V.D. knowledge in medical men generally, and in particular those who have the care of seafarers, must be of very great help.

\section{ON SHORE}

The seafarer in London readily seeks treatment, and does not usually delay in doing so. As proof I cite the fact that since I923 I have seen no case of primary syphiloma in a White seaman whose blood, even after an arsenobenzol injection, gave a Wassermann positive reaction.

The few secondary syphilitic cases seen in White seafarers since 1923 have been late relapses, there was no chancre, all had had insufficient treatment for primary syphiloma six months to a year, or more, previously. Again, for five or six years I have seen in the White seaman no chancroid which, according to the patient's statement, had been present and untreated by a doctor or steward for more than a few days.

Their statements also show that with first gonorrheal infections they have sought treatment (from doctor or steward) within forty-eight hours of noticing the discharge.

I have found no indication that the seafarer regards V.D. any more lightly than does the landsman.

The seafarer patients at my clinic may be divided into the following classes:-

(I) A small minority rejected on account of V.D., or suspected V.D., by the examining doctor before signing on.

(2) Those who on account of some lesion appearing on the genitalia, or skin elsewhere on the body (e.g., scabies, pityriasis rosea), after a more or less recent coitus, fear that they have contracted V.D.

(3) Those who intend to get married, and those who fear that a more or less recent coitus may have infected them with V.D. although no lesion of any kind be manifest.

(4) A small number who seek treatment for actual or 


\section{BRITISH JOURNAL OF VENEREAL DISEASES}

suspected V.D., but return to their ships to continue voyage to another port or ports. If V.D., these are given the V. 44 Personal Card, duly entered up with essential details of the case, for continuation treatment at other ports.

(5) Those who, while in a ship due to sail for another port, seek treatment for V.D. and ask for a medical certificate of unfitness to remain at sea. This certificate is given them, the ship pays them off, they come into hospital or lodge on shore near by (or proceed with a $V .44 \mathrm{Card}$ to their homes-this is very rare). Anyhow, they come under treatment.

(6) Those (the majority) who, sailing out and back from the Port of London, have contracted V.D. abroad or in England in between voyages, and who come for treatment. The fact that they must pass the examining doctor before signing on a ship undoubtedly keeps many seafarers under treatment who otherwise would discontinue treatment far too soon.

The seafarer does not like to go home, or even near his home, for treatment while suffering from V.D. Nor does he like going into hospital. He asks for in-patient treatment only when his money is exhausted (they may draw sick insurance money for V.D.) ; or when to be sick in hospital is the only way to avoid going home-for example, to a wife or to parents.

I am quite convinced, after ten years' experience of him in the Port of London, that the White seafarer is becoming less thoughtless and indifferent on the matter of his own responsibility for the spread of V.D. He makes an effort to remain under treatment until not only his primary or secondary syphilis is healed, but he also is made reasonably safe from relapse; he will also continue treatment until his chancroid be healed, for " sores" are easily. noted by the signing-on examining doctor. With gonorrhœa matters are not so satisfactory, mainly because treatment is not so satisfactory. The majority do not wait for the final tests of cure. After six weeks or more treatment, if no discharge be present, the seafarer very often discontinues treatment. However, many of these have returned to my clinic months or years later and then been found uninfected with gonorrhœa. There are some reasonable grounds, then, for believing that some of these gonorrhœa cases who discontinue 


\section{VENEREAL DISEASE IN MERCANTILE MARINE}

treatment are no longer infective, or cease to be infective soon after discontinuing treatment.

As to the "continuation" treatment V.44 Cards, they are coming more into use. More seafarers bring them to my clinic from other ports and clinics, and more take them away with them. But they are still viewed with some suspicion by the patient; they are often too damning an evidence of guilt to be happily kept, and so are often lost.

I have the impression that the clinics at foreign-nonBritish-ports are being attended more often of late by British seamen, and that some British oversea port clinics, for instance that at Singapore, are doing valuable work for V.D. in seafarers ; but there are, it seems, some oversea British ports where, so far, little or nothing is done. My impression is that, British or non-British, where there is a good clinic, seafarers attend it.

To sum up-V.D. in the Mercantile Marine is, in my observation, a reflection of V.D. in the landsman. Every successful measure against V.D. on shore, therefore, will have quick response in reduction of V.D. among seafarers. Meanwhile the special V.D. needs of the Mercantile Marine are :-

(I) V.D. treatment centres, with beds for in-patients, really accessible to the seafarer in all the main seaports. That is to say, the centre must be near to the ships' berths.

(2) These centres to co-operate with the medical officers who examine crews before they are signed on a ship. This signing-on medical examination is most important. It detects V.D. and it keeps V.D. under treatment.

(3) The better education in V.D. of ships' surgeons, and the better supply of ships with adequate and modern materia medica and apparatus for the treatment of such V.D. as may become manifest in the crew at sea. Beyond this, no formal acknowledged and advertised facilities for continuation treatment of contagious V.D. can be demanded of ships.

In conclusion, I would emphasise that we have one valuable asset to help us in our measures against V.D. in the Mercantile Marine: namely, the actual existing willing co-operation of the great majority of the seafarers themselves. This willingness on their part calls for increased effort on our part to meet it. 